\title{
Entrevista a João Branco Pedro
}

\section{Conduzida por Patrícia Bento d'Almeida' e Teresa Marat-Mendes'2, a 15 de outubro de 2020}

João Branco Pedro é Investigador Auxiliar do LNEC e Coordenador do Núcleo de Estudos Urbanos e Territoriais. Possui Licenciatura em Arquitetura pela FAUL (1994), Doutoramento em Arquitetura pela FAUP (2001) e Estágio de Pós-Doutoramento na TUDelft (2008). Ingressou no LNEC em 1994, onde tem participado em projetos de investigação científica e trabalhos de consultoria para entidades externas. Também participou em grupos de trabalho de apoio à revisão de regulamentação. Divulgou os resultados da sua atividade em publicações, comunicações e cursos em Portugal e no Brasil. O seu principal domínio de investigação é a habitação, em particular nas áreas de formulação e avaliação da qualidade da habitação, e da organização e aplicação da regulamentação técnica da construção. Lecionou em cursos de doutoramento da FAUL e da FAUUSP. Desempenhou funções em Gabinetes de Secretários de Estado com a tutela da habitação e da reabilitação urbana.
Patrícia Bento d'Almeida é Arquiteta e Investigadora Integrada no DINÂMIA'CET-Iscte. Com Mestrado (2007) e Doutoramento em História da Arte Contemporânea (2013) pela Faculdade de Ciências Sociais e Humanas da Universidade Nova de Lisboa, os principais temas de investigação centram-se em temáticas da História da Arquitectura e do Urbanismo Contemporâneo.

Teresa Marat-Mendes é Professora de Projecto Urbano e Urbanismo Ecológico no Departamento de Arquitectura e Urbanismo do ISCTE-IUL. Doutora pela Universidade de Nottingham com a tese 'The sustainable urban form'. A sua principal linha de investigação é o estudo da forma urbana, do metabolismo e da sustentabilidade. Actualmente, coordena no DINÂMIA'CETIscte a investigação transdisciplinar do Projecto SPLACH - Spatial Planning for Change.

\footnotetext{
1 patricia.bento.almeida@iscte-iul.pt.

2 teresa.marat-mendes@iscte-iul.pt
}

Copyright (C) 2021 (Almeida, P.B.; Marat-Mendes, T.) 


\section{É investigador do Laboratório Nacional de Engenharia Civil (LNEC) há mais de 25 anos, a temática da habitação tem sido um dos assuntos mais tratados. Como e com quem deu início a este tema de pesquisa?}

No LNEC, a investigação sobre habitação, nas vertentes da arquitetura, do urbanismo e das ciências sociais, teve início há aproximadamente 60 anos. Durante as décadas de 60 e 70 do século passado, a investigação procurou apoiar a atividade de projeto de habitação com informação técnica diversa, produzida com base na pesquisa junto dos moradores, no estudo das necessidades dos utentes e das funções da habitação, e na criação de instrumentos e metodologias de análise e otimização.

Nas décadas de 80 e 90, a investigação teve continuidade através do aprofundamento do conceito de qualidade do habitar, do desenvolvimento de metodologias de análise e avaliação multidisciplinar da qualidade habitacional e da produção de documentação normativa e recomendativa.

Nas primeiras duas décadas do século XXI, a investigação abordou sobretudo os novos desafios que se colocam ao habitar, destacando nomeadamente a humanização do habitar, a sustentabilidade da habitação, a reabilitação do edificado, as necessidades especiais de pessoas vulneráveis (idosos, as pessoas com mobilidade condicionada, pessoas em situação de sem-abrigo), e a integração de grupos étnicos minoritários através da habitação.

Tendo ingressado no LNEC em 1994, colaborei nos estudos que estavam em curso para diversas entidades externas sobre a qualidade da habitação, coordenados pelo Arq. Reis Cabrita. Paralelamente tive oportunidade de aprofundar a minha formação através da leitura da bibliografia de referência, da participação em encontros e debates, e do contacto com colegas mais experientes. A tese de doutoramento que desenvolvi, sobre avaliação da qualidade arquitetónica da habitação, surgiu na continuação de um trabalho precedente do Arq. Baptista Coelho. Após a conclusão da tese continuei a participar em estudos solicitados por entidades externas, nos quais pude pôr em prática os conhecimentos que tinha adquirido na tese. Simultaneamente contribuí para a linha de investigação sobre os novos desafios da habitação.

Ao rever este breve relato penso que ele ilustra alguns aspetos da cultura institucional do LNEC, nomeadamente uma investigação orientada para dar resposta aos desafios da sociedade, equilibrando contribuições para a resposta aos desafios atuais colocados por entidades externas, com investigação de iniciativa interna visando contribuir para a resposta a desafios futuros. Estas linhas de investigação são planeadas a médio prazo e contam com a colaboração de equipas multidisciplinares que desenvolvem investigação interdisciplinar.

\section{Na sua proposta de avaliação da qualidade arquitetónica habitacional as questões da sustentabilidade} são tratadas?

O «Método de Avaliação da Qualidade Arquitetónica Habitacional», que refere, foi desenvolvido entre 1995 e 1999, no âmbito da minha tese de doutoramento.

A abordagem assenta no conceito de qualidade residencial, entendido como a adequação da habitação e da sua envolvente à satisfação das necessidades imediatas e previsíveis dos moradores, compatibilizando as necessidades individuais com as da sociedade.

Embora o conceito de sustentabilidade não seja explicitamente referido, são incluídos no modelo de avaliação diversos indicadores que para ela contribuem, tais como os relativos ao conforto (térmico, acústico, visual) e à adequação social (uso, flexibilidade e apropriação). A dimensão económica, embora não incluída no modelo de avaliação, foi abordada na fase de definição de requisitos de qualidade.

Contudo, sem dúvida que há objetivos da sustentabilidade que não foram tratados na tese. Foi precisamente por reconhecer essa limitação que, logo após a conclusão da tese, dinamizei um projeto de investigação sobre os desafios que se colocavam à habitação para o futuro, sendo o da sustentabilidade ambiental um deles (vd. resposta seguinte). 


\section{Figura 1. Capa da tese de doutoramento e de um livro anexo}
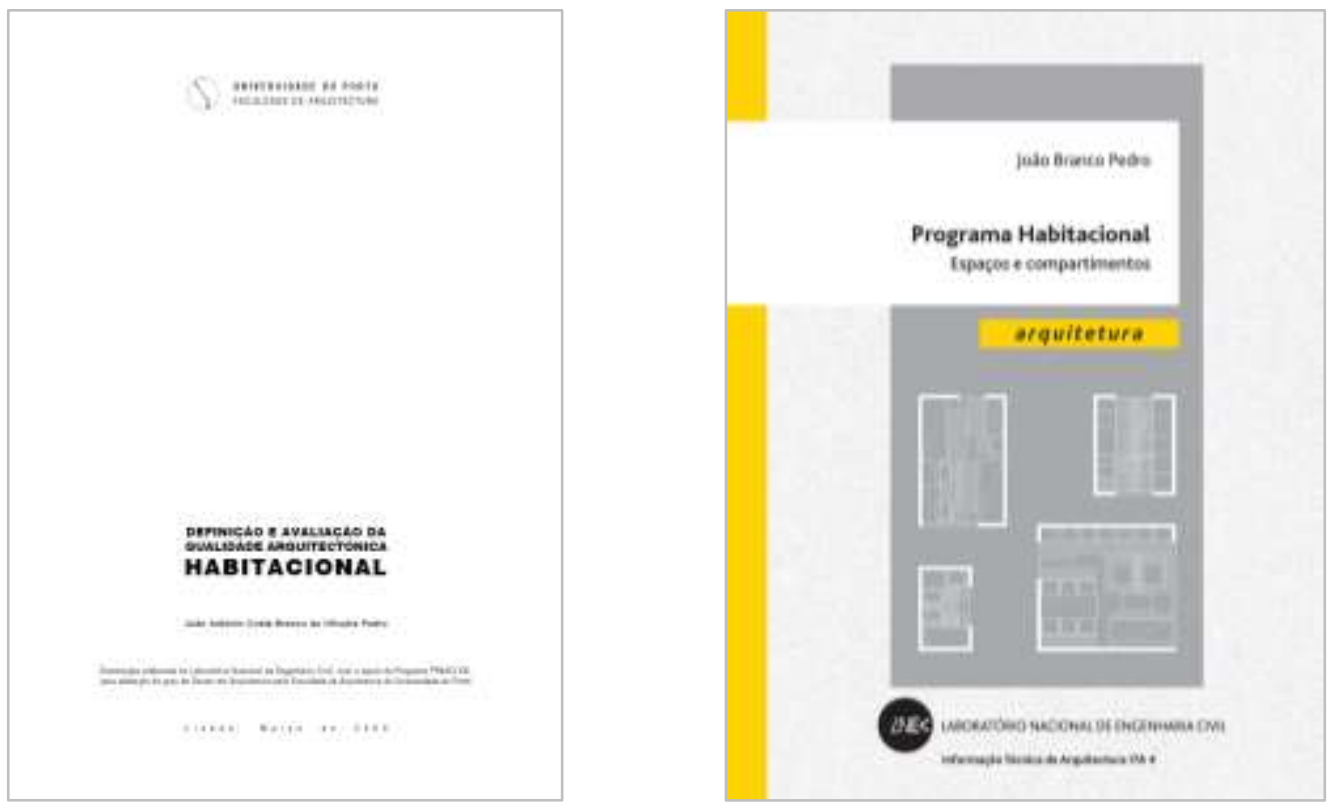

Fonte: LNEC

\section{A investigação científica desenvolvida no Núcleo de Estudos Urbanos e Territoriais (NUT) do LNEC tem procurado oferecer respostas às prementes problemáticas da sustentabilidade?}

Em linha com a vocação do LNEC, a atividade desenvolvida no NUT procura dar resposta aos desafios da sociedade, nomeadamente nos domínios da construção, da habitação e urbanismo, do ambiente e da gestão dos riscos. Sendo a sustentabilidade um desafio incontornável, tem sido abordada em numerosos estudos desde longa data, tanto no Núcleo de Arquitetura e Urbanismo como no Núcleo de Ecologia Social, unidades de investigação que se fundiram em 2013 para formar o NUT.

Não é naturalmente viável referir aqui todos esses estudos e os seus contributos. Porém, fazendo um balanço do conjunto, podemos observar que: (i) trataram os três pilares da sustentabilidade (ambiental, social e económico), assim como a dimensão institucional; (ii) abordaram as escalas do edifício, da cidade e do território; e (iii) tiveram como resultado o aprofundamento de conceitos, recomendações de boas práticas, métodos de avaliação e projetos de demonstração.

Apenas como exemplo e para ajudar a ter uma ideia mais concreta sobre o que tem sido feito a este respeito, refiro em seguida quatro estudos.

1. No estudo «Habitação para o futuro» (2003-2005) foi analisado como alcançar uma habitação mais ecológica (com menos impactes ambientais negativos), mais inteligente (que aproveita as novas tecnologias para aumentar a adequação aos modos de vida e promove a sustentabilidade ambiental) e mais adequada (capaz de responder à diversidade de modos de vida presentes e à sua transformação no futuro).

2. No estudo «Governação da Água em Angola: o peso das configurações institucionais e territoriais» (2005-2009) foi abordada a relação entre populações e os recursos hídricos, enquanto recursos naturais renováveis, tendo em conta os contextos territoriais e o papel dos sistemas institucionais.

3. No estudo «NZES - NetZero Energy Schools: Reaching the Community» (2009-2013), coordenado pelo Instituto Superior Técnico, foram identificadas as medidas tecnológicas e de alteração de comportamentos 
que podiam contribuir para o aumento da eficiência energética em contexto escolar e residencial, através de um modelo de avaliação e de intervenção multidisciplinar.

4. No estudo «BINGO - Bringing innovation to onGOing Water management. A better future under climate change» (2015-2019), coordenado pelo Departamento de Hidráulica e Ambiente do LNEC, foram estudadas medidas adaptativas face às alterações climáticas relacionadas com a gestão da água, tendo sido abordados especificamente todos os pilares da sustentabilidade.

Importa salientar que estes trabalhos foram desenvolvidos em parceria com outras entidades e contaram com o apoio de agências de financiamento à investigação.

Tal como no passado, atualmente o NUT participa em investigação cujo foco é a sustentabilidade. As abordagens e os contributos continuam a ser diversificados, destacando contudo as seguintes: a gestão inteligente da água sobretudo através da sua reutilização, o uso de materiais de baixo carbono na produção de elementos construtivos modulares num contexto de economia circular, o diagnóstico e avaliação de impactes culturais e ambientais da reabilitação de edifícios, a monitorização e gestão de emergência associadas ao galgamento e inundação provocados pela agitação marítima em zonas costeiras e portuárias, e conjugar a ciência e as comunidades locais na redução do risco de incêndios florestais.

Figura 2. Capas de documentos produzidos nos estudos

\section{«Habitação para o futuro» e «BINGO»}
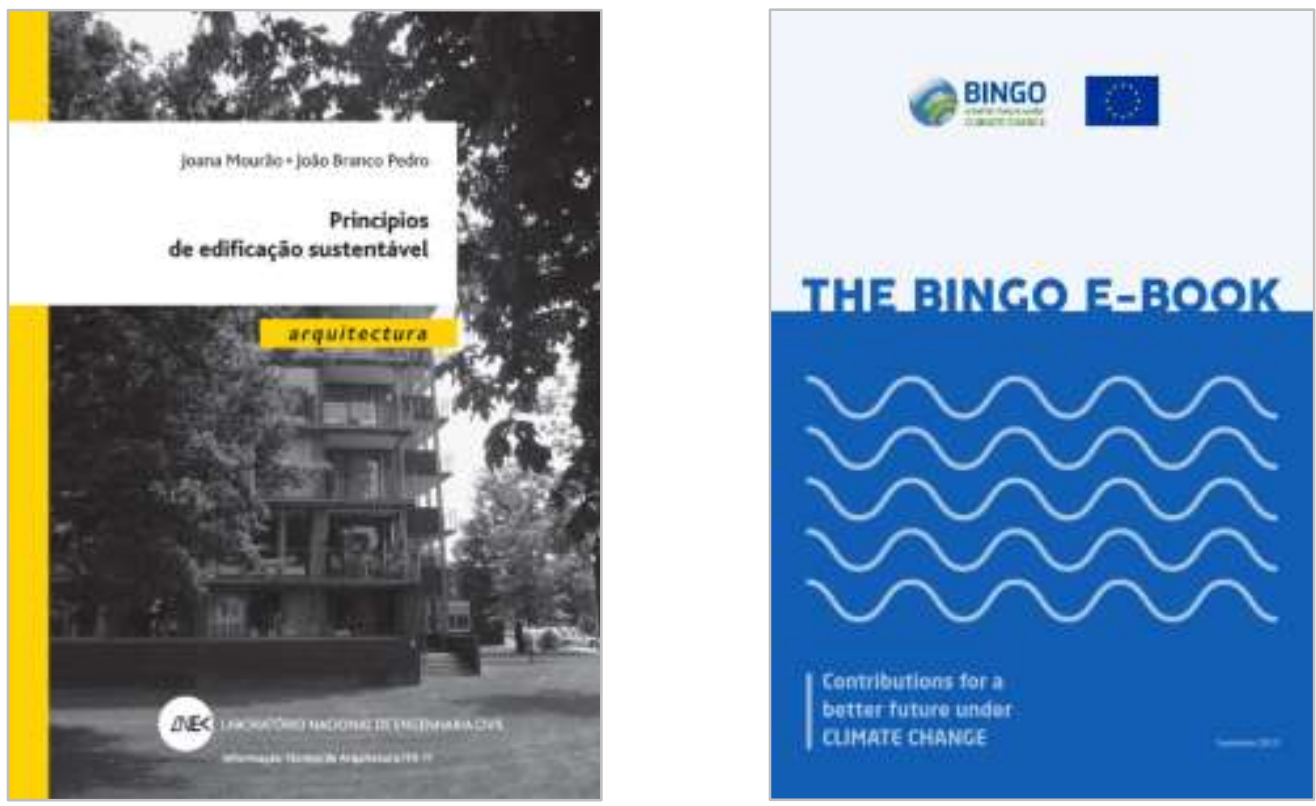

Fonte: LNEC

Qual a responsabilidade dos investigadores do NUT na pesquisa da sustentabilidade da habitação? Os trabalhos desenvolvidos procuram alertar a responsabilidade política?

O LNEC apoia naturalmente a prossecução das políticas públicas, em especial no que diz respeito à qualidade e segurança das construções e obras públicas, bem como a proteção e requalificação do património natural e construído. Esta missão orienta as atividades do NUT, refletindo-se, a meu ver, nas três formas de atuação dos investigadores, seguidamente referidas. 
Em primeiro lugar, desenvolvendo investigação cujos resultados contribuem para ajudar as entidades públicas e privadas a dar resposta aos desafios que enfrentam. Essa investigação pode resultar tanto de solicitações externas como de propostas dos próprios investigadores com vista a antecipar necessidades futuras.

Em segundo lugar, disseminando os resultados, através de publicações e palestras, que contribuem para informar a comunidade da construção. Os investigadores também organizam e ministram ações de formação pós-graduada nas quais participam com frequência quadros técnicos de municípios e empresas.

E ainda, em terceiro lugar, exercendo funções em órgãos do Estado ou em outras instituições exteriores ao LNEC. O exercício destas funções permite contribuir para a aplicação nas políticas públicas dos conhecimentos desenvolvidos nas atividades de investigação, bem como para um melhor conhecimento sobre os problemas do meio técnico nacional e dos processos de decisão e implementação das políticas públicas.

\section{Qual a importância da interdisciplinaridade nos estudos desenvolvidos no NUT?}

No nosso entendimento, a complexidade dos problemas colocados pelas sociedades contemporâneas exige uma combinação entre a especialização e o diálogo interdisciplinar, para produzir conhecimento que venha a apoiar a política pública.

Este entendimento está presente desde há muito na matriz do LNEC e justificou a integração, logo nos anos 60 do século passado, das disciplinas da arquitetura, do urbanismo e das ciências sociais. Durante 60 anos percorreu-se um caminho de progressiva especialização, embora sempre com fortes ligações e numerosos cruzamentos. A criação do NUT veio reforçar a ligação natural entre estas disciplinas, tendo em vista proporcionar uma visão integrada da interação entre sociedade e território.

A investigação conduzida no NUT evidencia esta forte ligação. A generalidade dos trabalhos é desenvolvida por equipas formadas por investigadores com diferentes formações e são também adotados métodos que promovem a integração de várias perspetivas na análise dos problemas.

Também aqui, muitos seriam os estudos cujos resultados dependeram de uma forte componente interdisciplinar, mas refiro como exemplo apenas três.

1. Os estudos de «Análise retrospetiva do parque financiado pelo INH» visaram analisar a qualidade da habitação a custo controlado construída, tendo no seu conjunto abrangido o período de 1985 a 1998 (19942005). Partindo-se de uma noção ampla de qualidade, a análise conjugou a apreciação do processo de promoção, das caraterísticas físicas e funcionais dos empreendimentos, do comportamento das soluções construtivas e das instalações, e da satisfação residencial dos moradores. Para este efeito as equipas de trabalho foram compostas por investigadores da arquitetura, engenharia civil e ciências sociais.

2. O estudo «KnowRisk - Know your city, reduce seismic risk through non-structural elements» (20162018) visou explorar e testar formas eficazes de divulgação científica em matéria de segurança sísmica e comportamentos protetivos na habitação. O seu desenvolvimento assentou num diálogo interdisciplinar entre a engenharia sísmica, as ciências sociais e a arquitetura determinante para a inovação em matéria de comunicação do risco sísmico alcançada.

3. O estudo «Life Impetus - Improving current barriers for controlling pharmaceutical compounds in urban wastewater treatment plants» (2016-2019), coordenado pelo Departamento de Hidráulica e Ambiente do LNEC, visou testar medidas para melhorar a remoção de componentes farmacêuticos em ETAR de águas residuais urbanas com sistemas de tratamento convencionais por lamas ativadas e avaliar a respetiva recetividade social. Suscitando o reaproveitamento das águas residuais uma forte reatividade social foi essencial integrar a componente das ciências sociais, que antecipou cenários e ajudou a gerir os diversos interesses e perceções sociais sobre as causas comportamentais a montante e as possíveis reutilizações da água. 
Em síntese, penso que o cruzamento das abordagens e conhecimentos especializados das diferentes disciplinas proporciona respostas mais completas e adequadas às questões que são tratadas. Acresce que o diálogo entre colegas com diferentes formações e especializações abre novas perspetivas e estimula um processo continuo de aprendizagem.

Figura 3. Capas de documentos produzidos nos estudos «Análise retrospetiva do parque financiado pelo INH» e «Life Impetus»
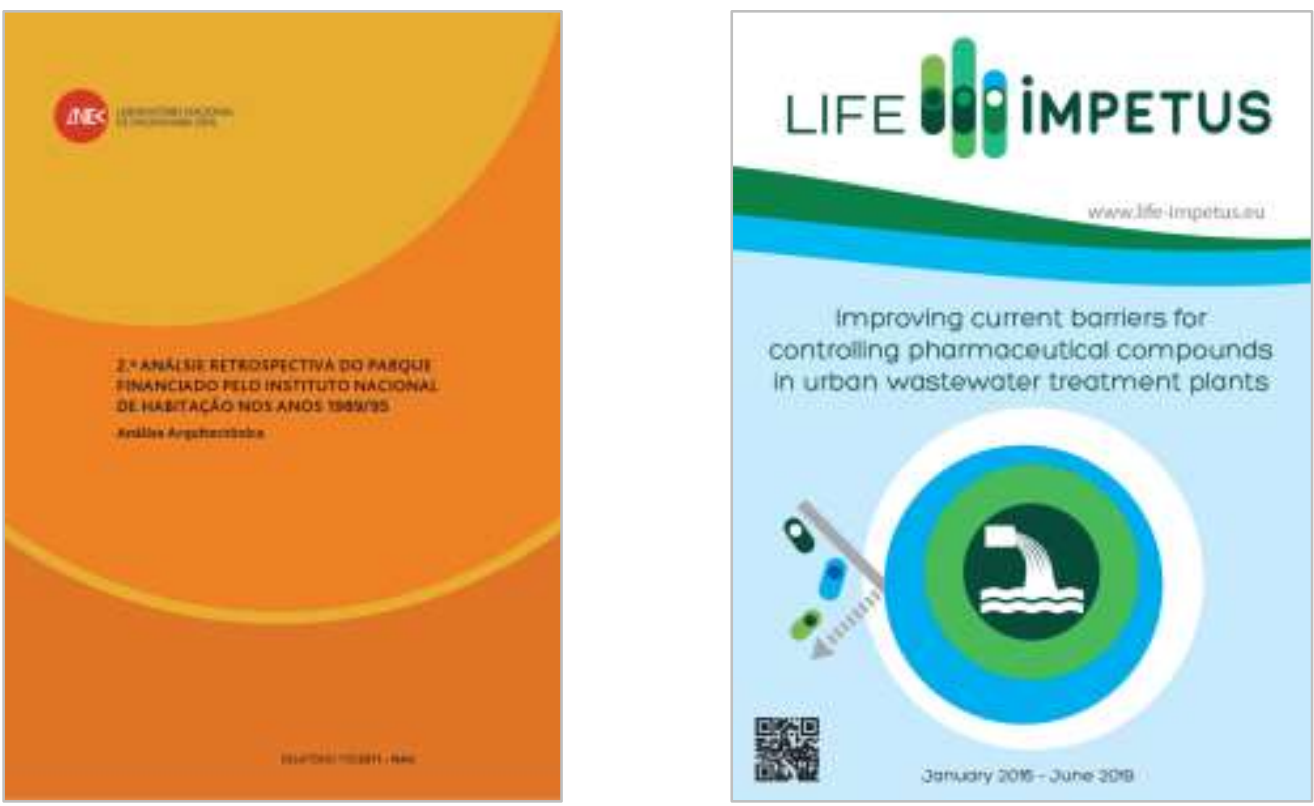

Fonte: LNEC

Na sua opinião, como é que a ciência pode auxiliar as instituições políticas a desenvolver um planeamento territorial mais sustentável?

Penso que o conhecimento científico é um apoio incontornável à decisão. Aliás, diversos estudos que realizámos no NUT tiveram precisamente como objetivo apoiar a conceção, implementação e avaliação de políticas públicas, sobretudo nos domínios da habitação e do planeamento territorial.

Esses estudos tiveram contributos de natureza diversificada, tais como a identificação de boas práticas, a caraterização de territórios, a conceção de programas, a monitorização e avaliação dos resultados, e a elaboração de recomendações ou propostas de normativos legais. Foram também diversificadas as entidades públicas que solicitaram a colaboração do NUT, desde a Administração Central, os institutos e empresas públicas, a as autarquias locais.

Tal como nas repostas anteriores, refiro alguns exemplos de estudos com contributos diretos para um planeamento territorial mais sustentável.

1. No trabalho sobre "Habitat \& Minorias" procurou-se conhecer a relevância que o habitat tem nos processos de integração de populações de matriz africana e cigana, residentes nas Áreas Metropolitanas de Lisboa e do Porto, com fracas capacidades económicas de escolha residencial, tendo resultado recomendações de política pública, de gestão do existente e para futuras intervenções (1999-2000). 
2. No âmbito da regulamentação do Regime de Arrendamento Urbano, aprovado pela Lei n. $.^{\circ} 6 / 2006$, foi desenvolvido o «Método de avaliação do estado de conservação de edifícios», que foi primeiro aplicado em caso de atualização extraordinária do valor das rendas e depois adotado em diversos outros regimes legais relacionados com gestão urbanística (2005-2007).

3. Em colaboração com o Instituto da Habitação e da Reabilitação Urbana (IHRU), foi realizada uma análise das condições de habitabilidade do edificado do Bairro do Alto da Cova da Moura, com vista a constituir uma base para o subsequente planeamento urbano (2007-2008).

4. Foi acolhido um estudo sobre metabolismo urbano que procurou estabelecer bases para um ordenamento do território e planeamento urbano municipal efetivamente comprometidos com a sustentabilidade ecológica dos territórios (2007-2011).

5. O NUT colaborou também na elaboração das Principais Opções do Ordenamento do Território de Angola, tendo sido responsável pela coordenação técnica geral e participado no diagnóstico, na definição de objetivos estratégicos de desenvolvimento territorial, e na proposta de estratégia e modelo territorial (2014-2016).

6. Refiro ainda a participação no estudo «Reabilitar como Regra» sobre a adequação das normas técnicas da construção às exigências e especificidades da reabilitação de edifícios, tendo o NUT tido particular envolvimento no domínio da segurança contra incêndio do qual resultaram alterações legislativas e instrumentos atualmente em aplicação no licenciamento de intervenções de reabilitação (2017-2019).

Figura 4. Capas de documentos produzidos nos estudos «Habitat \& Minorias» e «Reabilitar como Regra»
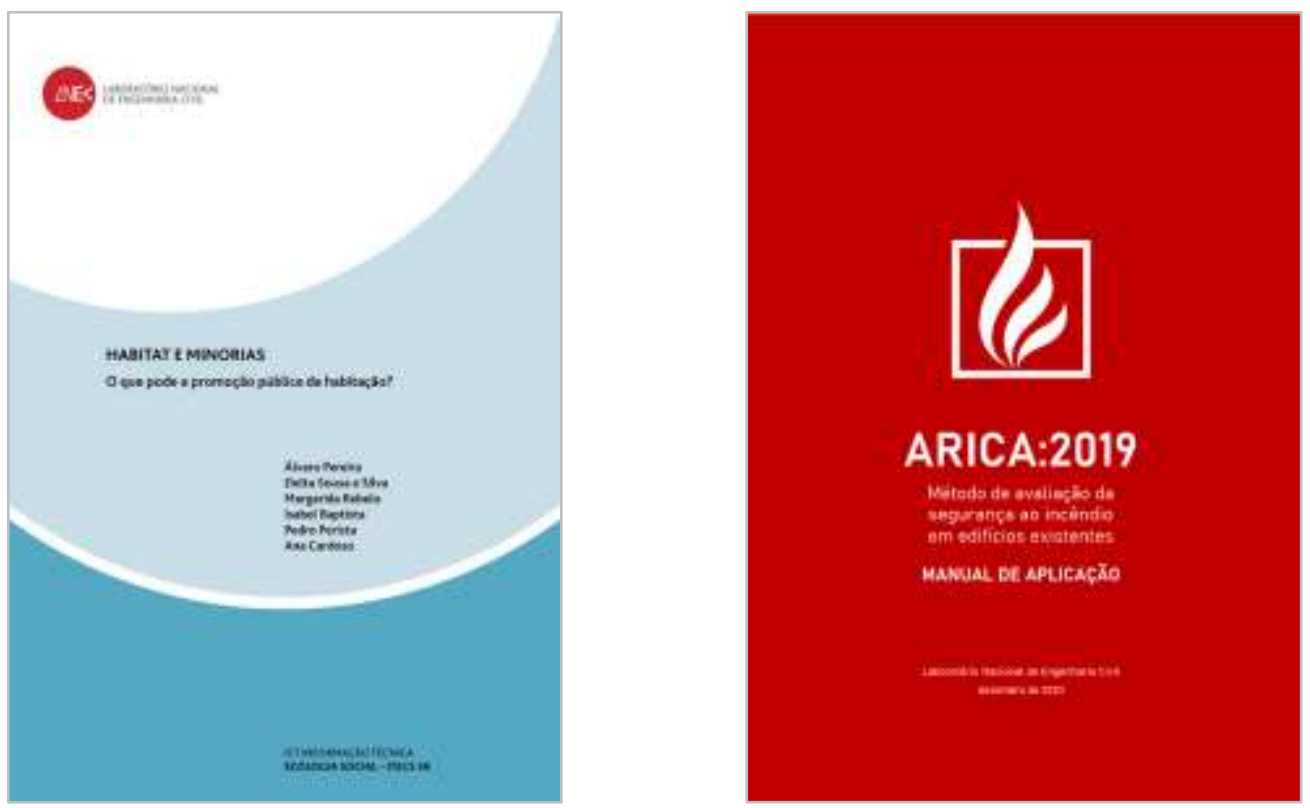

Fonte: LNEC

A este respeito, gostaria de sublinhar que, no NUT, reconhecemos a importância da diversidade de fontes de informação e o contributo do conhecimento da experiência prática dos atores para a compreensão dos fenómenos que analisamos. Assim, têm vindo a ser testados no NUT métodos participativos. 
Um exemplo desta abordagem foi o estudo «Apoio técnico ao dispositivo de acompanhamento e avaliação em intervenção comunitária no território da Anunciada (Setúbal)», que teve lugar nos Bairros do Grito do Povo e dos Pescadores. O objetivo foi acompanhar as iniciativas de melhoria dos espaços públicos destes bairros, envolvendo a participação dos moradores, serviços camarários e outros atores locais. O NUT colaborou na montagem e facilitação de um roteiro de oficinas colaborativas com os moradores e técnicos da autarquia conducentes à elaboração de ideias e iniciativas experimentais de qualificação integrada do território.

Como conclusão, gostava de observar que é comummente reconhecido que o LNEC tem prestado, ao longo de várias décadas, importantes serviços ao País nos domínios da engenharia civil. Penso que nesta missão, a arquitetura, o urbanismo e as ciências sociais têm dado o seu contributo para a compreensão da organização e funcionamento do ambiente construído assim como das dinâmicas de mudança de comportamentos e de valores sociais. Essa compreensão proporciona uma intervenção com melhor conhecimento sobre as interdependências entre a sociedade, o ambiente e o território. 